\title{
Variability of Level of Tibial Tuberosity
}

\author{
AHMED E. AHMED, M.Sc.; HESHAM A. EL-KADY, M.D.; MOHAMMED M. ABD EL-HAMID, M.D. and \\ DORREIA A.M. ZAGHLOUL, M.D.*
}

The Department of Orthopedics, El-Mabara Hospital, Assiut and The Department of Human Anatomy \& Embryology, Assiut University Hospitals*, Assiut

\begin{abstract}
Background: Life assessment of this parameters were related to its importance in many orthopaedic surgical procedures, as tibial tuberosity level is used as a landmark in high tibial osteotomy and total knee replacement.

Aim of Study: Epidemiological study for assessment of the following levels in adult Egyptians which may affect many orthopedic surgical procedures. Level of tibial tuberosity from the tibial plateau to tibial tuberosity.

Patients and Methods: Our study is a Prospective descriptive cross sectional study. We studied level of tibial tuberosity of the knee in 500 cases divided as 231 males and 269 female egyptian subjects between the ages of 20 to 60 years. The cases were selected from the records of the Orthopaedic Department of Assiut University Tertiary Hospitals in Egypt during 2016-2017.
\end{abstract}

Results: The tibial tuberosity level ranges from 22 to $31 \mathrm{~mm}$. Male hight range from 21 to $33 \mathrm{~mm}$. Femal hight range from 22 to $28 \mathrm{~mm}$

Conclusion: As regard to the tibial tuberosity level in comparison to other study we revealed that Egyptian tibial tuberosity height is higher than that of the Chinese.

Key Words: Variability - Tibial - Tuberosity.

\section{Introduction}

THE proximal tibia and the patella have a lot of landmarks which are used in several surgical procedures in orthopaedics, one of these is the tibial tuberosity which is a uniform landmark in certain procedures like the high tibial osteotomy [1], and total knee arthroplasty [2] in which the location of the tibial tuberosity is one of the most important parameters to restore the knee joint line level in cases of bone loss, and in case of the need to put an undersized tibial component, so we will measure the tibial tuberosity level in the Egyptians by measuring the distance between the joint line and

Correspondence to: Dr. Ahmed E. Ahmed,

The Department of Orthopedics, El-Mabara Hospital, Assiut the tip of the tibial tuberosity in life cases as will be described later on.

Patella form a part of the patellofemoral joint which plays an important role in the knee extensor mechanism. The patella acts as the lever arm in extensor arc motion and improves quadriceps strength by $30-50 \%$ [3]

To our knowledge, no similar study has been conducted to measure these parameters in the egyptian population.

\section{Patients and Methods}

Our study was Prospective descriptive cross sectional study, we studied lateral radiographs of 500 knees divided as 231 males and 269 female Egyptian subjects between the ages of 20 to 60 years. The cases were selected from the records of the orthopaedic department of Assiut University Tertiary Hospitals in Egypt during 2016-2018, the radiographs had been taken in the investigation of musculoskeletal problems in the limbs and only those that were adjudged normal were selected.

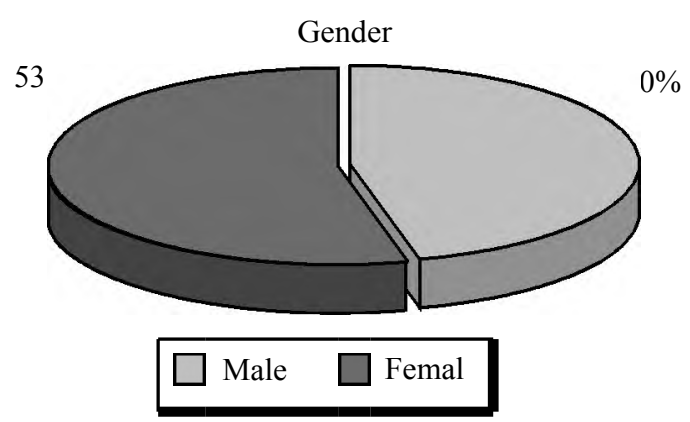

Fig. (1): Sex distribution.

Level of tibial tuberosity: (From the tibial plateau to the tip of the tibial tuberosity) were measured as follow by using depth gage and measurement device as shown in (Figs. 2,3). 


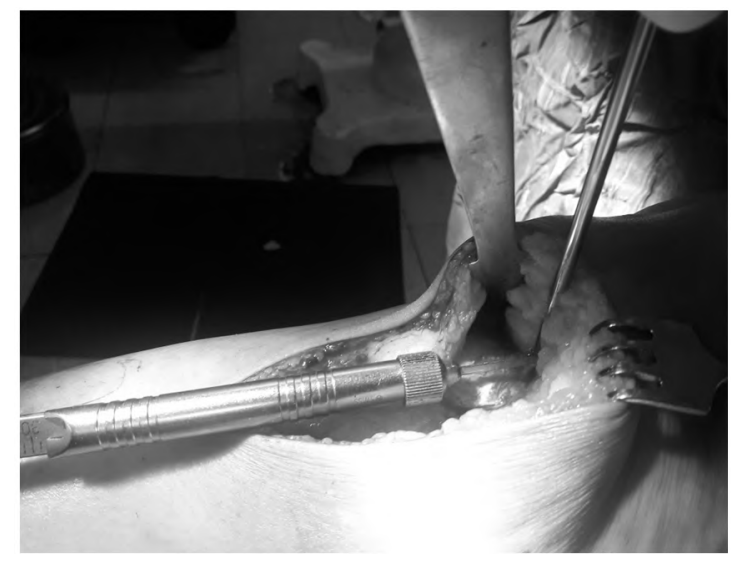

Fig. (2): Tibial tuberosity measurement by using depth gauge from the tibial plateau to the tip of the tibial tuberosity in life surgery.

\section{Results}

The tibial tuberosity level ranges from 22 to $31 \mathrm{~mm}$. The tibial tuberosity level ranges from 22 to $31 \mathrm{~mm}$. Male hight range from 21 to $31 \mathrm{~mm}$. Femal hight range from 22 to $28 \mathrm{~mm}$ (Table 1).

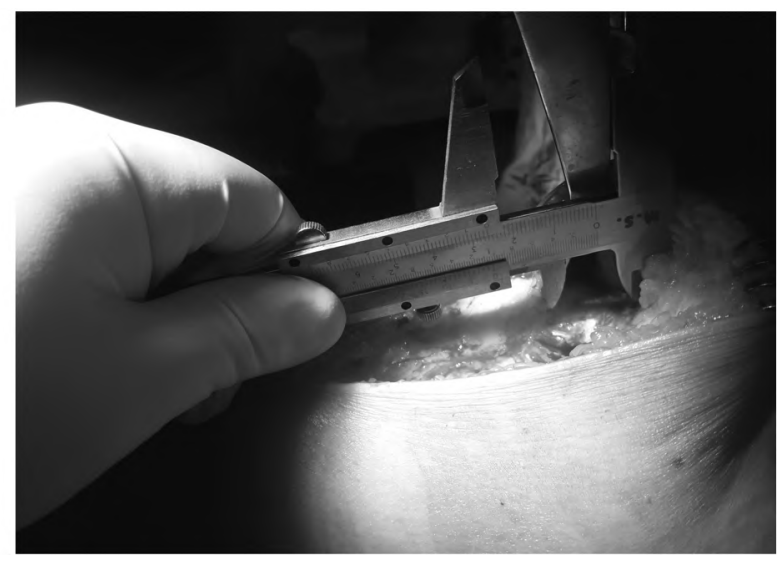

Fig. (3): Tibial tuberosity measurement by using measurement device from the tibial plateau to the tip of the tibial tuberosity.

Table (1): Level of tibial tuberosity.

Range

Tibial tuberosity

22 to $31 \mathrm{~mm}$

Chart title

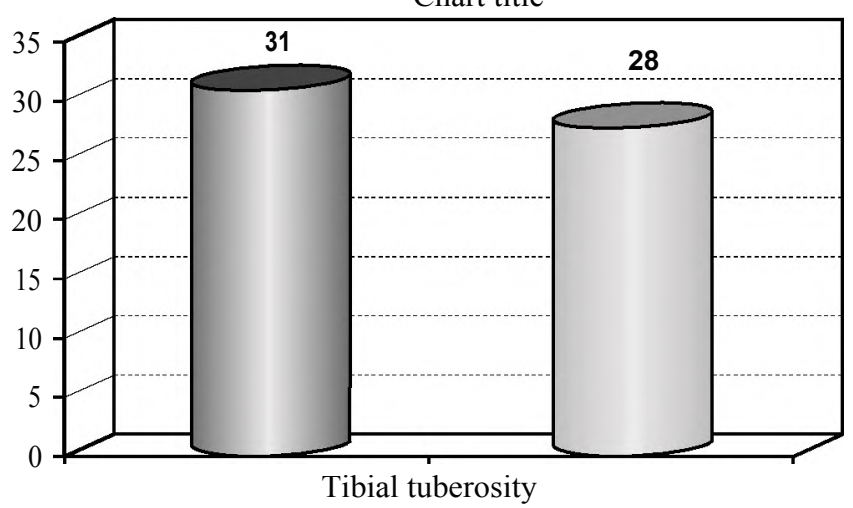

Diagram (1): Variation in the tibial tuberosity between males and females.

Tibial tuberosity level 1

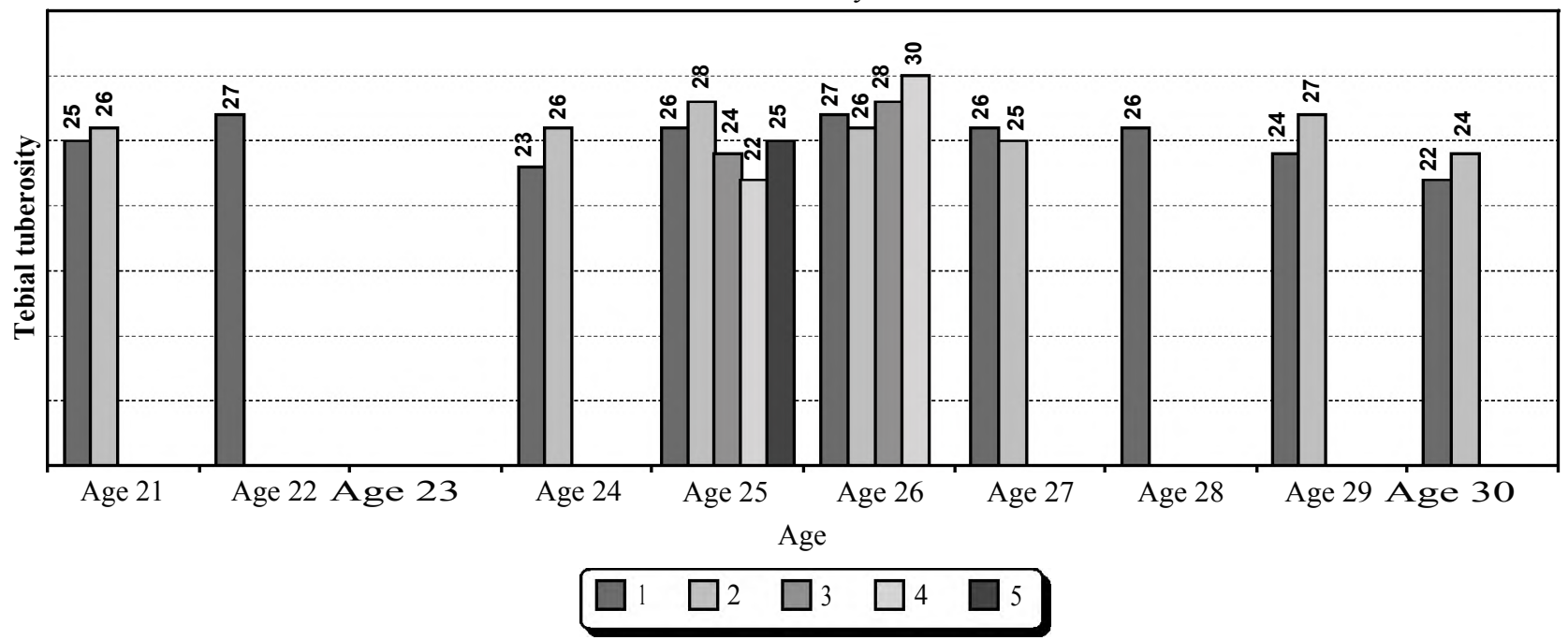

Diagram (2): Variability of the tibial tuberosity level concerning age group (21-30 years). 


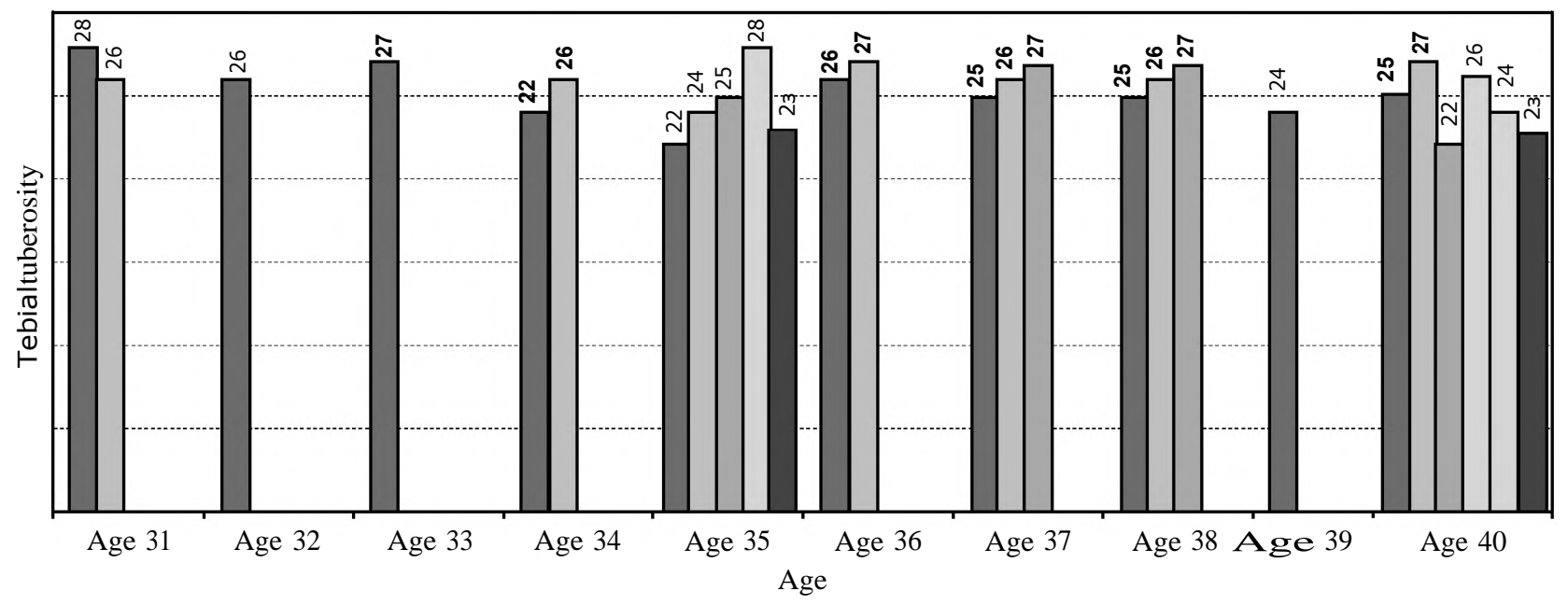

Diagram (3): Variability of the tibial tuberosity level concerning Age (age 31-age 40).

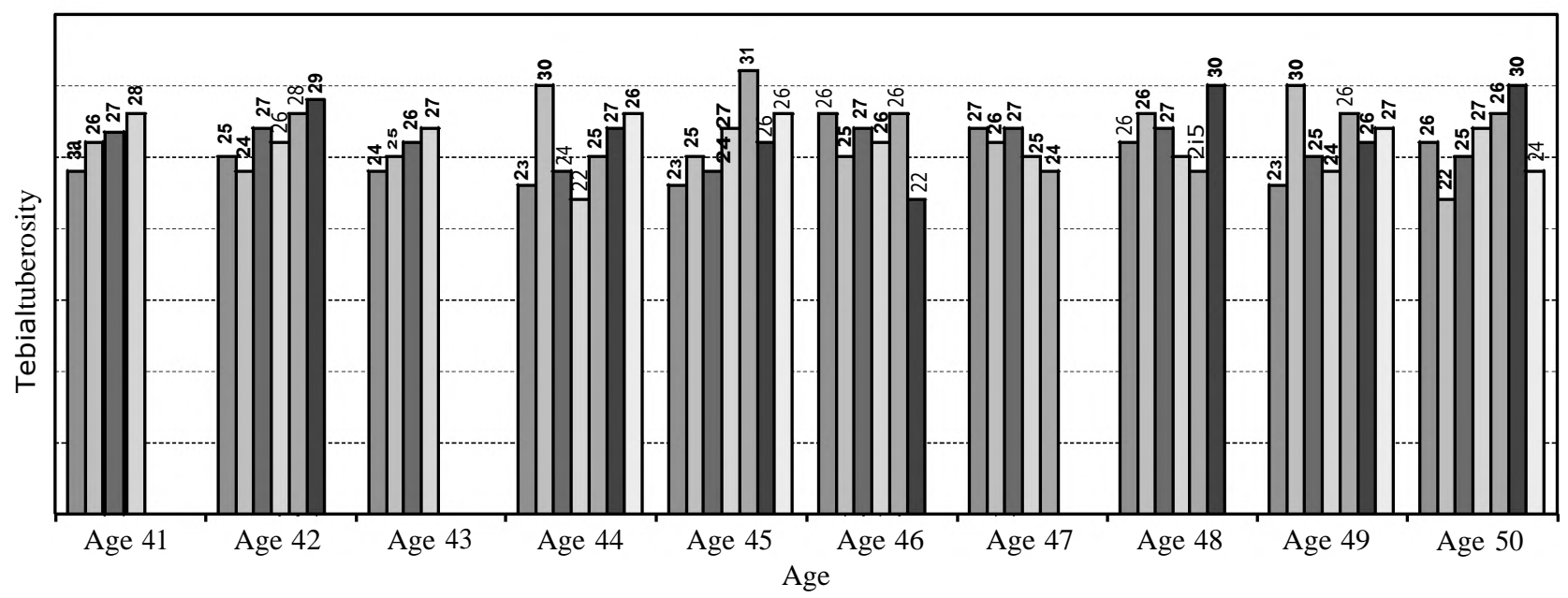

Diagram (4): Variability of the tibial tuberosity level oncerning age group (41-50 years).

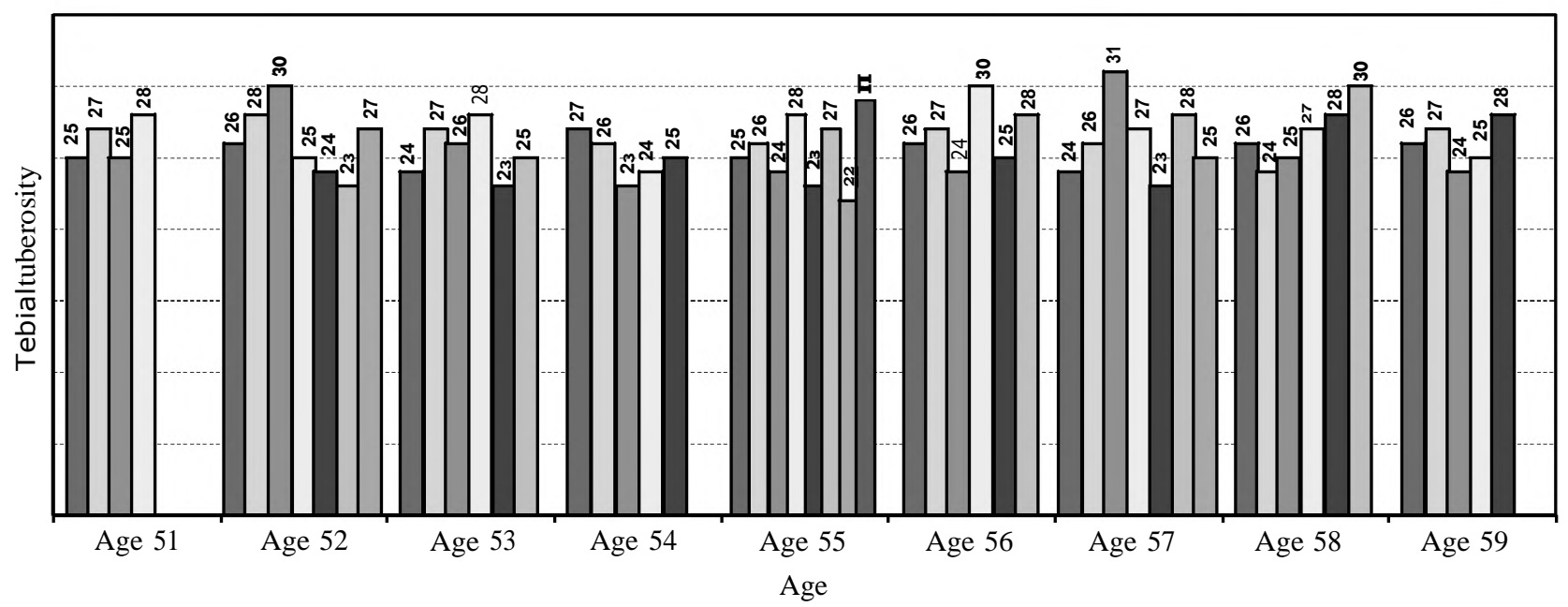

Diagram (5): Variability of the tibial tuberosity level concerning age group (51-60 years). 


\section{Discussion}

Our study included 500 knees, and the aim of our sudy is life assessment of the study including, tibial tuberosity.

Tibial tuberosity level variation will affects many surgical procedures as in high tibial osteotomy, total knee replacement in which restoration of the knee joint line is very important and in our study we detect the average range of the tibial tuberosity level from the joint line in Egyptians.

Determination of the knee joint line position is critical in high (supra tubercular) osteotomy:

1- Medial open wedge high tibial osteotomy in treatment of genu varum.

2- Medial closed wedge high tibial osteotomy in treatment of genu valgum.

3- Lateral closed wedge high tibial osteotomy in treatment of genu varum.

Determination of the knee joint line position is also critical in total knee prosthesis surgery, particularly in revision knee prosthesis surgery. Complications such as decreased strength of the extensor mechanism, compression on the patella, anterior knee pain, and decreased range of motion of knee joint may arise in cases in which the level of the joint line is not properly determined $[7,8]$ Proper position of the joint line is determined through measurement of the distances between these anatomic points.

Tibial tuberosity ranges from 22 to $31 \mathrm{~mm}$ males in females it ranges from 22 to $28 \mathrm{~mm}$ males and females, tibial tuberosity height is larger in males than in females.

In another studies we detect these variation, Havet et al., [9] found a large variability of the distance from the tibial tubercle to the joint line $(3.35 \pm 0.5 \mathrm{~cm}$, range from $2.1-4.7 \mathrm{~cm})$ in their radiographic study.

Knee joint line position measured from the tibial side in Chinese people, the distance to the joint line was $2.048 \pm 0.164 \mathrm{~cm}$ from the tibial tubercle. They reported that the tibial tubercle is a reliable landmark for this measurment [10]

In comparison with our study knee joint line in Chinese is lower than that of the Egyptians.

Mason et al., studied 6 cadaver knees and noted that the joint line was an average of $3.24 \mathrm{~cm}$ from the tibial tubercle [11].
Our study, Compared with the other studies, revealed that the knee Joint line position in the Chinese population was lower than those in the Egyptians and Western population. This was to be expected because the anatomical features of Asian Populations differ from those of Western populations [12-15]. Therefore, referring to the data of Western population, revision TKA for Chinese people would probably lead to elevation of the knee joint line.

Servien et al also found a wide variation in the tibial tubercle joint Line distance value from $1.061 \mathrm{~cm}$ to $3.209 \mathrm{~cm}$ (mean $2.189 \mathrm{~cm}$ ) [16]

In comparison with our study knee joint line in Egyptians is higher than those measured by Servien et al.

\section{Conclusion:}

The aim of our study is life assessment of the tibial tuberosity level, patellar height and tibial slope in Egyptians and from our study we reveal that these measurements are very important as landmarks in many orthopaedic surgical procedures as described befor and our results can be used as areference values in comparison with other study in different population.

Conflict of interest: All of the authors declare that they have no conflict of interest. No benefits in any form have been or will be received from a commercial party related directly or indirectly to the subject of this manuscript.

Ethical approval: By the Ethical Committee of Faculty of Medicine at Assiut University.

\section{References}

1- DEBEYRE J. and PATTE D.: Intérêt des ostéotomies de correction dans le traitement de certaines gonarthroses avec deviation axiale. Rev. Rhum. Mal. Osteoartic. Vol., 29: pp. 722-729, 1962.

2- BELLEMANS J.: Restoring the joint line in revision TKA: Does it matter? Knee, 11: 3, 2004.

3- KREVOLIN J.L., PANDY M.G. and PEARCE J.C.: Moment arm of thepatellar tendon in the human knee. J. Biomech., 37: 785-788, 2004.

4- PORTNER O. and PAKZAD H.: The evaluation of patellar height: A simple method. J. Bone. Joint. Surg. Am., 93: 73-80, 2011

5- NOYES F.R., GOEBEL S.X. and WEST J.: Opening wedge tibial osteotomy: The 3-triangle method to correct axial alignment and tibial slope. Am. J. Sports Med., 33 (3): 378-87, 2005.

6- LASKIN R.S.: Management of the patella during revision total knee replacement arthroplasty. Orthop. Clin. North. Am., 29: 355-60, 1998. 
7- LASKIN R.S.: Joint line position restoration during revision total knee replacement. Clin. Orthop. Relat. Res., 404: 169-71, 2002.

8- HAVET E., GABRION A., LEIBER-WACKENHEIM F., et al.: Radiological study of the knee joint line position measured from the fibular head and proximal tibial landmarks. Surg. Radiol. Anat., 29: 285, 2007.

9- Int. J. Morphol., 27 (1): 201-204, 2009.

10- MASON M., BELISLE A., BONUTTI P., et al.: An accurate and reproducible method for locating the joint line during a revision total knee arthroplasty. J. Arthroplasty, 21: 1147, 2006.

11- NAGAMINE R., MIURA H., BRAVO C.V., et al.: Anatomic variations should be considered in total knee arthroplasty. J. Orthop. Sci., 5: 232, 2000.
12- KO P.S., TIO M.K., BAN C.M., et al.: Radiologic analysis of the tibial intramedullary canal in Chinese varus knees: implications in total knee arthroplasty. J. Arthroplasty, 16: 212, 2001.

13- MATSUDA S., MIZU-UCHI H., MIURA H., et al.: Tibial shaft axis does not always serve as a correct coronal landmark in total knee arthroplasty for varus knees. J. Arthroplasty, 18: 56, 2003.

14- TANG W.M., ZHU Y.H. and CHIU K.Y.: Axial alignment of the lower extremity in Chinese adults. J. Bone. Joint. Surg. Am., 82: 1603, 2000.

15- SERVIEN E., VISKONTAS D., GIUFFRÈ B.M., et al.: Reliability of bony landmarks for restoration of the joint line in revision knee arthroplasty. Knee. Surg. Sports Traumatol. Arthrosc., 16: 263, 2008.

\title{
تنوع وأختلاف مستوى حدبة الساق
}

\author{
الهدف من دراستنا هو التقييم داخل غرفة العمليات لمرضى الذين يعانون من خشونة الركبة لمستويات حدبة عظام الساق، في المصريين

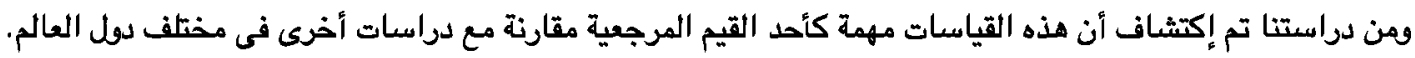 \\ وفيما يتعلق بمستوى حدبة عظام الساق فقد وجدنا فى هذه الدراسة أن هذه المسافة تتراقح ما بين بو حتى آمم بالمقارنة مع دراسة

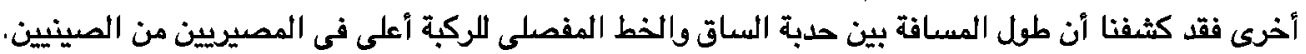

